\title{
Ropivacaine infiltration analgesia of the drainage exit site enhanced analgesic effects after breast Cancer surgery: a randomized controlled trial
}

\author{
Baona Wang ${ }^{1 \dagger}$, Tao Yan $^{1 \dagger}$, Xiangyi Kong ${ }^{2+}$, Li Sun $^{3}$, Hui Zheng ${ }^{1 *}$ and Guohua Zhang ${ }^{1 *}$
}

\begin{abstract}
Background: Postoperative pain after breast cancer surgery remains a major challenge in patient care. Local infiltration analgesia is a standard analgesic technique used for pain relief after surgery. Its application in patients who underwent mastectomy requires more clear elucidation. This study aimed to investigate the effect of ropivacaine infiltration of drainage exit site in ameliorating the postoperative pain after mastectomy.

Methods: A prospective randomized controlled study was conducted in 74 patients who were scheduled for unilateral mastectomy by standardized general anesthesia. Both intervention group and control group were given infiltration of the two entry points of drainage catheters with $10 \mathrm{ml} 0.5 \%$ ropivacaine (Group A) $(n=37)$ or $10 \mathrm{ml}$ normal saline (Group B) $(n=37)$. Pain scores were recorded in post-anesthesia care unit (PACU), at $6 \mathrm{~h}, 12 \mathrm{~h}, 24 \mathrm{~h}$ and $36 \mathrm{~h}$ after operation by using a visual analogue scale (VAS). Postoperative nausea and vomiting (PONV) incidence, postoperative analgesic and antiemetic requirements, the incidence of chronic pain, as well as the quality of recovery were recorded.
\end{abstract}

Results: The patients in Group A showed a significant reduction in postoperative pain in PACU $(p<0.0005)$, at $6 \mathrm{~h}$ $(p<0.0005), 12 \mathrm{~h}(p<0.0005)$, and $24 \mathrm{~h}$ after surgery $(p<0.05)$ when compared to those in Group B. There were more postoperative analgesic requirements in Group B $(p<0.05)$. With regard to the quality of recovery, Group $A$ was shown to be much superior over Group B ( $p<0.05)$.

Conclusions: Ropivacaine infiltration of the two drainage exit sites decreased the degree of postoperative acute pain after mastectomy, and this approach improved patients' quality of recovery.

Trial registration: retrospectively registered in Chictr.org.cn registry system on 24 February 2020 (ChiCTR2000030139). Keywords: Local infiltration analgesia, Ropivacaine, Drainage exit site, Postoperative pain, Breast cancer

\footnotetext{
*Correspondence: zhenghui0715@hotmail.com; d1974@163.com

†Baona Wang, Tao Yan and Xiangyi Kong contributed equally to this work. 'Department of Anesthesiology, National Cancer Center/National Clinical Research Center for Cancer/Cancer Hospital, Chinese Academy of Medical Sciences and Peking Union Medical College, Beijing 100021, China Full list of author information is available at the end of the article
}

C C The Author(s). 2020 Open Access This article is licensed under a Creative Commons Attribution 4.0 International License, which permits use, sharing, adaptation, distribution and reproduction in any medium or format, as long as you give appropriate credit to the original author(s) and the source, provide a link to the Creative Commons licence, and indicate if changes were made. The images or other third party material in this article are included in the article's Creative Commons licence, unless indicated otherwise in a credit line to the material. If material is not included in the article's Creative Commons licence and your intended use is not permitted by statutory regulation or exceeds the permitted use, you will need to obtain permission directly from the copyright holder. To view a copy of this licence, visit http://creativecommons.org/licenses/by/4.0/. The Creative Commons Public Domain Dedication waiver (http://creativecommons.org/publicdomain/zero/1.0/) applies to the data made available in this article, unless otherwise stated in a credit line to the data. 


\section{Background}

Postoperative pain is one of the most common challenges in women following breast cancer surgeries, which impairs rehabilitation and increases the length of hospital stay. About $50 \%$ of patients who receive mastectomy might experience persistent postoperative pain $[1,2]$. Sensory disturbances such as burning or sensory loss caused from the wound are commonly observed as sequelae of mastectomy, and this might be due to intraoperative nerve injury [3]. However, complaints of acute postoperative pain in patients who received mastectomy are also frequently observed. After mastectomy, a drainage tube is routinely placed, which assists in monitoring bleeding, and fluid or air removal. The wound is infiltrated or irrigated with local anesthetic to reduce acute postoperative pain, and is widely used in surgeries $[4,5]$. However, few studies have paid much attention in investigating whether postoperative pain could be effectively alleviated by infiltrating anesthesia at the drainage exit site after mastectomy. Based on our clinical experiences, the major location of the acute pain might be at the insertion sites of the two drainage catheters, which were placed below the skin flap at the end of the surgical procedure. For the firm anchorage of the drain to the skin and sealing of the space around the drain, the two entry points of catheter insertion were chosen over healthy skin below the inframammary fold of the breast, wherein most of the subcutaneous nerves were not damaged, meaning that they were still sensitive to pain. Park's study [6] reported that surgical drains are associated with high postoperative opioid use after breast cancer surgery, and this supported our observation.

Although multimodal analgesic strategies including opioids, acetaminophen, non-steroidal anti-inflammatory drugs (NSAIDs), peripheral regional techniques, patientcontrolled modalities as well as local anesthetic techniques such as wound infiltration are available, postoperative pain still has been poorly managed. Analgesiarelated side-effects such as nausea and vomiting, dizziness, constipation and itching are commonly observed, impairing patients' satisfaction and delaying their discharge time $[7,8]$. Postoperative pain after breast cancer surgery can be effectively alleviated by regional nerve block techniques, for example the thoracic paravertebral nerve block (PVB) [9]. But a long learning cycle and invasive nature of the method limited the implementation of PVB in breast cancer surgery.

This prospective randomized controlled study aimed to investigate if infiltration of ropivacaine at the insertion sites of the two drain catheters in mastectomy would reduce postoperative acute pain, postoperative nausea and vomiting (PONV), and chronic pain.

\section{Methods}

\section{Study design}

This prospective, randomized controlled trial was designed in adherence to the CONSORT guidelines and was registered in Chictr.org.cn registry system on 24 February 2020 (ChiCTR2000030139). This study was conducted in Cancer Hospital, Chinese Academy of Medical Sciences between September and November 2019 , and has been approved by the institutional ethics committee (IRB Approval Number: 20/351-2135). All patients were followed up until 3 months after discharge from the hospital.

\section{Participants}

Patients who underwent unilateral mastectomy with axillary lymph node dissection (ALND) or sentinel lymph node biopsy (SLNB) were enrolled in this study. Written informed consent was obtained from patients. The patients aged $20 \sim 70$ years, and with the American Society of Anesthesiologists physical status of I to III were included. Patients with the following conditions were excluded from the study: history of severe cardiovascular or pulmonary, hepatic, renal, neurologic, and psychiatric or metabolic diseases; history of allergy to any of the potential study medications; active drug abuse; intake of NSAIDs, opioids, or other analgesics in the $24 \mathrm{~h}$ before surgery; pregnancy; breastfeeding, active menstruation.

\section{Randomization}

Prior to study initiation, 80 sequentially numbered envelopes containing the allocation were prepared. The involved patients were randomly assigned to $10 \mathrm{ml} 0.5 \%$ ropivacaine infiltration (Group A) or $10 \mathrm{ml}$ normal saline infiltration (Group B) groups. A physician independent of the study randomly inserted 40 anesthesia strategies for each group into the envelopes. The random allocation sequence was generated using computer-generated random numbers. The researchers opened the envelope to determine as to which anesthesia strategy to implement before the induction of general anesthesia. All perioperative data were collected by an investigator who was blinded to the patient's allocation, and was responsible for measuring the outcome.

\section{Interventions}

Standard general anesthesia was induced using sufentanil $0.3 \sim 0.6 \mu \mathrm{g} / \mathrm{kg}$, propofol $1 \sim 2 \mathrm{mg} / \mathrm{kg}$ and cisAtracurium $0.2 \sim 0.4 \mathrm{mg} / \mathrm{kg}$ in the two groups. After laryngeal mask airway insertion, the patients were mechanically ventilated to maintain the end-tidal carbon dioxide concentration at $35 \sim 45 \mathrm{mmHg}$ with a fresh gas flow of $2 \mathrm{~L} / \mathrm{min} 60 \%$ oxygen. Anesthesia was maintained by constant inhalation of $1.5 \sim 2.5 \%$ sevoflurane and constant infusion of remifentanil at a rate of $0.1 \sim$ 
$0.2 \mu \mathrm{g} / \mathrm{kg} / \mathrm{min}$. Sufentanil $0.1 \mu \mathrm{g} / \mathrm{kg}$ was added intraoperatively as required. At the end of the surgery all patients received $100 \mathrm{mg}$ of flurbiprofen (an NSAID). Dexamethasone $8 \mathrm{mg}$ (given after induction) and ondansetron $4 \mathrm{mg}$ (given at the end of surgery) were used for prevention of postoperative nausea and vomiting (PONV). All surgical procedures were finished by the same surgical team with the same standardized technique. The two drainage catheters were placed by the surgeon before closing the surgical incision. Before the placement, the subcutaneous tissue of the two entry points of the catheters received local infiltration, which included intervention group (Group A) by $10 \mathrm{ml} 0.5 \%$ ropivacaine and control group (Group B) by $10 \mathrm{ml}$ normal saline $(5 \mathrm{ml}$ for each point). After operation, all patients were extubated and transferred to the post-anesthesia care unit (PACU). Flurbiprofen $100 \mathrm{mg}$ was provided by intravenous injection daily to control the postoperative pain within 3 days after operation. If the pain visual analogue scale (VAS) was $\geq 3,100 \mathrm{mg}$ tramadol was administered as a rescue analgesic. For postoperative antiemetic treatment, metoclopramide was intravenously administrated if the nausea VAS was $\geq 5$ or episodes of vomiting $\geq 2$. All patients received standard postoperative therapies according to the pathological characteristics.

\section{Outcomes}

\section{The primary outcomes}

The pain was immediately assessed after returning to PACU and at $6 \mathrm{~h}, 12 \mathrm{~h}, 24 \mathrm{~h}$, and $36 \mathrm{~h}$ after operation using a VAS $(0=$ no pain to $10=$ most severe pain). The incidence of PONV was recorded simultaneously, using a three-point ordinal scale $(0=$ none, $1=$ nausea, $2=$ retching, $3=$ vomiting), and nausea was evaluated by VAS. The number of patients who received postoperative analgesic or antiemetic drugs was recorded.

\section{Secondary outcomes}

The status of chronic pain in patients was collected using the breast cancer pain questionnaire, which was first developed by Gartner et al. [3]. A Pain Burden Index (PBI) can be calculated according to the data collected by the questionnaire surveys. It was calculated by adding the pain severity scale $(0 \sim 10)$ from anatomic locations of breast, axilla, chest wall and arm, and multiplied by the frequency of pain at each site (constantly- 5 points, daily -4 points, occasionally -3 points, weekly2 points, monthly -1 point, and never -0 points).

The quality of recovery including 40 questions (QoR40 ), which is used as a measure of quality of recovery, was distributed to patients for collecting data $24 \mathrm{~h}$ after operation. This included five factors of emotional state, physical comfort, psychological support, physical independence, and pain. In all, the highest score was 200 while the lowest being 40 and the more score, the better the results.

Also the remaining data, including the consumption of sufentanil during the surgery, types of surgical procedures, operation and anesthesia time, age, body mass index (BMI), history of smoking and PONV were collected,

\section{Sample size and statistical analysis}

The sample size was calculated based on our preliminary experiment that enrolled 10 cases in each group. The mean pain VAS at $12 \mathrm{~h}$ after the surgery was $1.2 \pm 2.1$ for Group A and $2.9 \pm 2.2$ for Group B. Using standard sample size calculation formula to achieve a power of 0.8 at $\alpha=0.05$, there should be at least 29 patients included in each group to detect a significant difference. Considering the possibility of data censored, a total of 40 patients in each group were recruited to guarantee the sample size. SPSS 23.0 for windows (SPSS, Inc., Chicago, IL, USA) was used for data analysis. Normally distributed continuous data were expressed as means (SD), and were analyzed using analysis of variance (ANOVA), independent-sample t-test or paired t-test. Nonparametric data were analyzed by Mann-Whitney and Wilcoxon text. Two-sided tests were performed to declare statistical significance at $p<0.05$.

\section{Results}

The random assignment of the participants into the two groups and analysis of the outcome was presented in Fig. 1. Finally, a total of 74 patients were included in this study. Demographic characteristics, including age, body weight, body height, BMI, smoking status, and history of PONV were comparable in both groups (Table 1). In addition, no significant differences were found in the consumption of sufentanil during surgery, the durations of anesthesia and surgery, and the types of surgical procedures used (Table 1).

Surgical drains were reported to be associated with high postoperative opioid use after breast-conserving surgery ${ }^{6}$. Although whether surgical drains increase opioid consumption after mastectomy has not been investigated, pain originating from the insertion sites of the two drainage catheters constitutes a major part of acute postoperative pain. In this study, we found that ropivacaine infiltration of the two drainage exit sites have significantly reduced the postoperative pain in PACU (VAS score, $0.54 \pm 1.07$ vs. $1.97 \pm 1.48, p<0.0005$ ), at $6 \mathrm{~h}$ (VAS score, $0.49 \pm 1.12$ vs. $2.24 \pm 1.36, p<0.0005$ ), $12 \mathrm{~h}$ (VAS score, $0.86 \pm 1.29$ vs. $2.30 \pm 1.35, p<0.0005)$, and $24 \mathrm{~h}$ after operation (VAS score, $1.35 \pm 1.27$ vs. $1.97 \pm 1.32$, $p<0.05$ ) (Fig. 2). However, at $36 \mathrm{~h}$ after operation, a significant difference was not observed any more (1.51 \pm 1.15 vs. $1.68 \pm 1.23, p>0.05$ ) (Fig. 2 ). More number of 


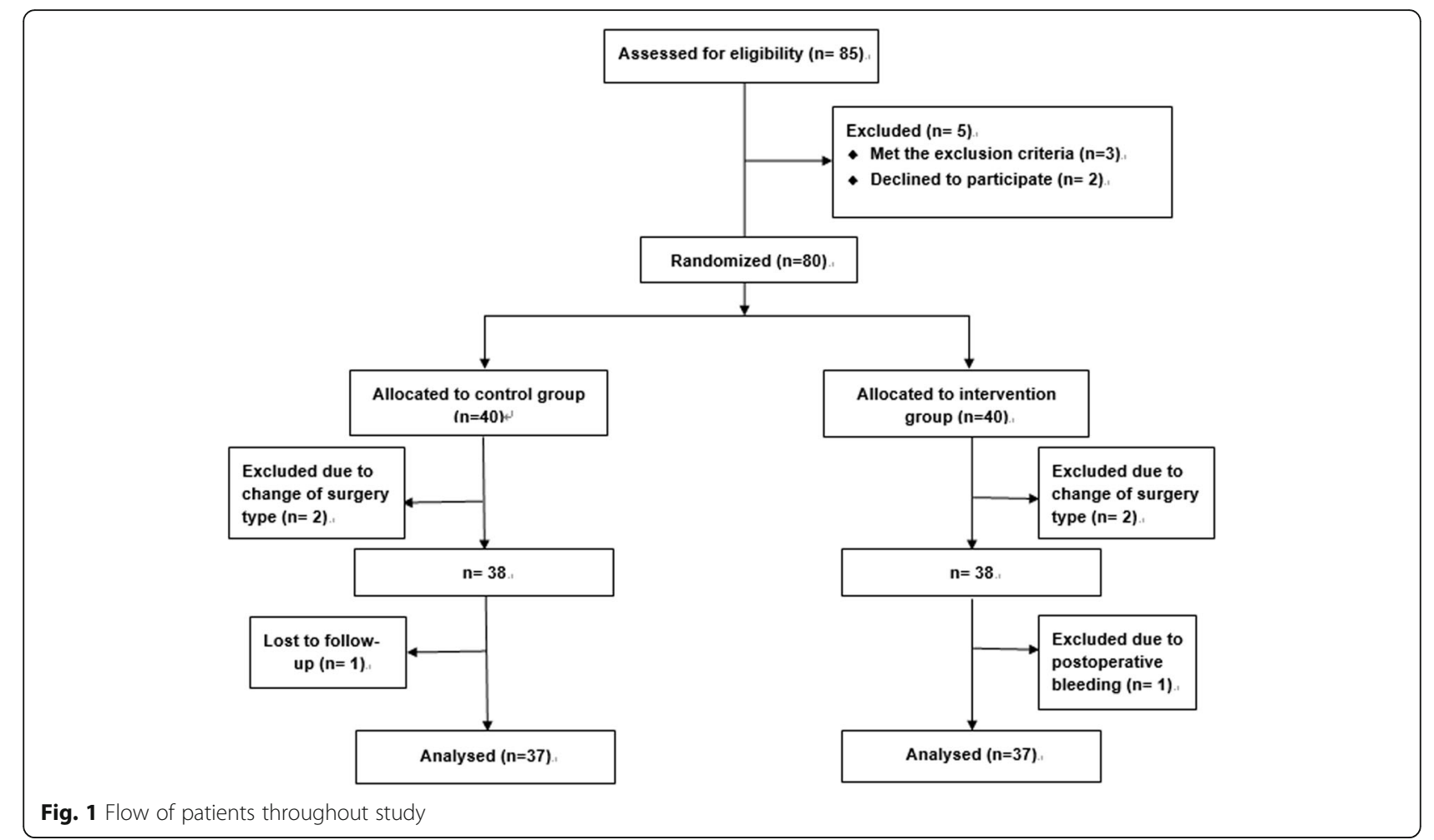

patients required for postoperative rescue analgesic in Group B than in Group A (17 vs. 7, $p<0.05$ ).

We did not collect pain scores of restricted movement of the shoulder and values of arm abduction angle. Because the operated arm was tightly bound and forbidden to move by surgeons within 3 days after the operations, in case of wound dehiscence, subcutaneous effusion and hematoma.

The intervention showed no effect on the incidence of chronic pain within 3 months, and PBI in the two groups showed similar results (Table 2). No significant differences were found between the two groups in terms of PONV incidence (Table 3) and the requirements for postoperative antiemetic treatment. The QoR-40 score of Group A was significantly higher than Group B $(185.8 \pm 8.3$ vs $179.7 \pm 11.2, p<0.05)$.

\section{Discussion}

To our knowledge, this is the first prospective randomized controlled study to reveal ropivacaine infiltration of

Table 1 Baseline characteristics of patients in the study and the control groups

\begin{tabular}{|c|c|c|c|}
\hline & Group $A(n=37)$ & Group $B(n=37)$ & $P$ value \\
\hline Age (years) ${ }^{\mathrm{a}}$ & $52.1 \pm 9.0$ & $49.1 \pm 9.9$ & 0.17 \\
\hline Weight (kg) ${ }^{a}$ & $61.8 \pm 8.7$ & $59.8 \pm 8.4$ & 0.32 \\
\hline Height $(\mathrm{cm})^{a}$ & $160.3 \pm 5.5$ & $159.4 \pm 5.0$ & 0.44 \\
\hline Body mass index ${ }^{a}$ & $24.0 \pm 3.6$ & $23.9 \pm 3.1$ & 0.82 \\
\hline Smoking (\%) & 0 & 0 & - \\
\hline History of PONV (\%) & $5(13.5 \%)$ & $4(10.8 \%)$ & 0.48 \\
\hline Surgical procedure & & & 0.41 \\
\hline mastectomy + axillary dissection (\%) & $30(80.1 \%)$ & $27(73.0 \%)$ & \\
\hline mastectomy + SNLB (\%) & $7(19.9 \%)$ & $10(27.0 \%)$ & \\
\hline Surgery time $(\min )^{a}$ & $98.1 \pm 31.3$ & $111.0 \pm 28.8$ & 0.07 \\
\hline Length of anesthesia (min) ${ }^{a}$ & $113.5 \pm 30.1$ & $125.5 \pm 27.9$ & 0.08 \\
\hline Consumption of Sufentanil $(\mu \mathrm{g})^{a}$ & $24.8 \pm 5.7$ & $23.8 \pm 5.0$ & 0.42 \\
\hline
\end{tabular}

Values are expressed as the mean \pm standard deviation; PONV postoperative nausea and vomiting; SNLB sentinel lymph node biopsy 


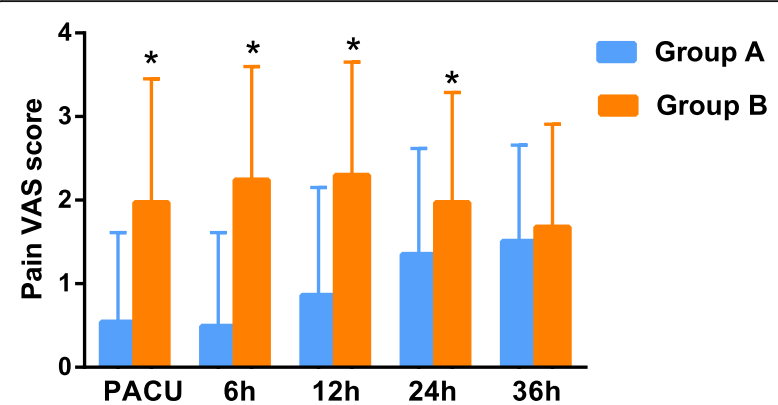

Fig. 2 Pain VAS score of patients in the study and control groups. Compared with Group B, postoperative pain in Group A was significantly reduced in PACU (VAS score, $0.54 \pm 1.07$ vs. $1.97 \pm 1.48$, $p<0.0005)$, at $6 \mathrm{~h}$ (VAS score, $0.49 \pm 1.12$ vs. $2.24 \pm 1.36, p<0.0005$ ), $12 \mathrm{~h}$ (VAS score, $0.86 \pm 1.29$ vs. $2.30 \pm 1.35, p<0.0005)$, and $24 \mathrm{~h}$ after operation (VAS score, $1.35 \pm 1.27$ vs. $1.97 \pm 1.32, p<0.05) .{ }^{*} p<0.05$; Group A: intervention group (ropivacaine infiltration); Group B: control group (normal saline infiltration); PACU: Post-anesthesia care unit; VAS: Visual analogue scale

the two drainage exit sites, which significantly reduced postoperative pain and analgesic requirements and improved the quality of recovery after mastectomy.

Park's study [10] reported that compared with other breast surgical procedure types, mastectomy required consumption of more opioids during the first week postoperatively. Opioid consumption plays an important role in postoperative pain control after mastectomy. However, opioid-related adverse effects led to other problems that delay the recovery, and so novel analgesics or strategies with less side-effects are urgently needed. Kairaluoma et al. [11] have found that PVB could improve postoperative pain and reduce opioid consumption after modified radical mastectomy. Nevertheless, compared with local infiltration anesthesia, the regional block technique is considered more challenging technically, and needs a longer learning period. According to our results, ropivacaine infiltration of the two drainage exit sites during mastectomy is a simple, easy, and economical approach for pain relieving, without any opioid-related adverse effects. Correspondingly, postoperative analgesic requirements were reduced, and the quality of recovery was improved.

Table 2 Incidence of chronic pain in the study and the control groups

\begin{tabular}{llll}
\hline & Group A $(\boldsymbol{n}=\mathbf{3 7})$ & Group B $(\boldsymbol{n}=\mathbf{3 7})$ & $\boldsymbol{p}$ value \\
\hline $\begin{array}{c}\text { Location } \\
\text { Chest wall }\end{array}$ & $8(21.6 \%)$ & $12(32.4 \%)$ & \\
$\quad$ Axillary & $9(24.3 \%)$ & $7(18.9 \%)$ & 0.30 \\
$\quad$ arm & $5(13.5 \%)$ & $4(10.8 \%)$ & 0.58 \\
Total & $19(51.4 \%)$ & $16(43.2 \%)$ & 0.72 \\
PBI $^{\mathrm{a}}$ & $7.3 \pm 9.7$ & $7.3 \pm 9.0$ & 0.49 \\
\hline
\end{tabular}

Values are expressed as the mean \pm standard deviation; $P B /$ Pain Burden Index
Table $\mathbf{3}$ Incidence of PONV in the study and the control groups

\begin{tabular}{llll}
\hline & Group A $(\boldsymbol{n}=\mathbf{3 7})$ & Group B $(\boldsymbol{n}=\mathbf{3 7})$ & $\boldsymbol{p}$ value \\
\hline In the PACU & & & \\
PONV & $9(24.3 \%)$ & $11(29.7 \%)$ & 0.93 \\
Asymptomic & $28(75.7 \%)$ & $26(70.3 \%)$ & \\
PACU-6 h & & & \\
PONV & $8(21.6 \%)$ & $8(21.6 \%)$ & 0.90 \\
Asymptomic & $29(78.4 \%)$ & $29(78.4 \%)$ & \\
$\mathbf{6}$ h-12 h & & & 0.12 \\
PONV & $6(16.2 \%)$ & $12(32.4 \%)$ & \\
Asymptomic & $31(83.8 \%)$ & $25(67.6 \%)$ & 0.46 \\
12 h-24 h & & & \\
PONV & $3(8.1 \%)$ & $5(13.5 \%)$ & \\
Asymptomic & $34(91.9 \%)$ & $32(86.5 \%)$ & \\
$\mathbf{2 4}$ h-36 h & & $1(2.7 \%)$ & \\
PONV & $0(0 \%)$ & $36(97.3 \%)$ & \\
Asymptomic & $37(100 \%)$ &
\end{tabular}

PONV postoperative nausea and vomiting; PACU post-anesthesia care unit

To compare with the previous similar studies, in Table 4 we summarized 8 randomized controlled trials that evaluated the efficacy of local analgesic for pain relief in breast cancer surgery, in which the local analgesic was either injected into the wound preoperatively or instilled through the drainage tube into the wound postoperatively. However, in this study, we chose to perform local infiltration anesthesia of the two drainage exit sites with ropivacaine, based on the evidence that pain caused by the drainage plays a vital role in postoperative pain. Five of the above mentioned trials [12-16] showed no differences between the control and experimental groups, in which Baudry et al.'s studies [12] enrolled patients who received breast-conserving surgery with or without ALND. However, the postoperative pain of different types of surgical technique remained different. The breast-conserving surgeries are susceptible to acute pain of the wound. In contrast, mastectomy surgeries are susceptible to burning, sensory loss or other abnormal sensations due to nerve damage, while acute pain is not reported as the main complaint [20]. Thus, it is not precise to compare the pain score between these two types of surgery due to the different mechanisms of pain. Our study is designed by including patients who received mastectomy, which provided comparable results. Nirmala et al. [17-19] have found that the local analgesic group showed significant reduction in the postoperative pain within $90 \mathrm{~min}, 6 \mathrm{~h}$, and $15 \mathrm{~h}$, respectively. Although the infiltration location in our study was different from theirs, local infiltration anesthesia showed effective results for patients who received mastectomy, and had a longer effective duration $(24 \mathrm{~h})$. 
Table 4 Characteristics of the selected randomized controlled trials

\begin{tabular}{|c|c|c|c|c|c|c|}
\hline Study & Research aim & Surgical technique & Intervention & Infiltration locations & Result & Ref \\
\hline $\begin{array}{l}\text { Baudry } \\
{[2008]}\end{array}$ & $\begin{array}{l}\text { evaluate the effect of } \\
R \text { wound infiltration }\end{array}$ & $\begin{array}{l}\text { MRM or partial } \\
\text { mastectomy with ALND }\end{array}$ & $\begin{array}{l}\text { R: } 4.75 \mathrm{mg} / \mathrm{mL} R \\
40 \mathrm{~mL} \\
\text { C: NS } 40 \mathrm{~mL}\end{array}$ & The wound & no differences & {$[12]$} \\
\hline $\begin{array}{l}\text { Johansson } \\
\text { [2003] }\end{array}$ & $\begin{array}{l}\text { whether infiltration } \\
\text { with } R+\text { fentanyl } \\
\text { improves PP }\end{array}$ & $\begin{array}{l}\text { Partial mastectomy with } \\
\text { or without ALND }\end{array}$ & $\begin{array}{l}\text { R1: } 0.375 \% \mathrm{R} \\
\text { R2: } 0.375 \% \mathrm{R}+ \\
\text { Fentanyl } 0.5 \mu \mathrm{g} / \mathrm{kg} \\
\text { C: Nil }\end{array}$ & The wound & no differences & [13] \\
\hline $\begin{array}{l}\text { Johansson } \\
\text { [2000] }\end{array}$ & $\begin{array}{l}\text { whether infiltration } \\
\text { with R improves PP }\end{array}$ & $\begin{array}{l}\text { Partial mastectomy with } \\
\text { or without ALND }\end{array}$ & $\begin{array}{l}\text { R: R } 3.75 \mathrm{mg} / \mathrm{mL} \\
\text { C: NS } 0.3 \mathrm{~mL} / \mathrm{kg}\end{array}$ & The wound of breast and axilla & no differences & [14] \\
\hline Rica [2007] & $\begin{array}{l}\text { if infiltration with } R \\
\text { could improve PP }\end{array}$ & Mastectomy and ALND & $\begin{array}{l}\text { R1: Preoperative } \\
0.2 \% \text { R } 20 \mathrm{~mL}+\mathrm{NS} \\
\text { to } 80 \mathrm{~mL} \\
\text { R2: Postoperative } \\
0.2 \% \mathrm{R} 20 \mathrm{~mL}+\mathrm{NS} \\
\text { to } 80 \mathrm{~mL}\end{array}$ & The wound & no differences & [15] \\
\hline $\begin{array}{l}\text { Talbot } \\
{[2004]}\end{array}$ & $\begin{array}{l}\text { determine the } \\
\text { influence of B } \\
\text { irrigation on PP }\end{array}$ & MRM & $\begin{array}{l}\text { B: } 0.5 \% \text { B } 20 \mathrm{~mL} \\
\text { C: NS }\end{array}$ & $\begin{array}{l}\text { Through the axillary drain into the } \\
\text { axillary wound }\end{array}$ & no differences & [16] \\
\hline $\begin{array}{l}\text { Nirmala } \\
\text { [2019] }\end{array}$ & $\begin{array}{l}\text { Whether wound } \\
\text { instillation with B } \\
\text { improve PP }\end{array}$ & MRM & $\begin{array}{l}\text { R: } 0.25 \% \text { B } 40 \mathrm{ml} \\
\text { C: } 40 \mathrm{ml} \text { normal } \\
\text { saline }\end{array}$ & $\begin{array}{l}\text { through chest and axillary drains into } \\
\text { the wound }\end{array}$ & $\begin{array}{l}\text { providing better } \\
\text { analgesia within } \\
15 \mathrm{~h}\end{array}$ & [17] \\
\hline $\begin{array}{l}\text { Vigneau } \\
{[2011]}\end{array}$ & $\begin{array}{l}\text { document the effect } \\
\text { of } R \text { infiltration }\end{array}$ & $\begin{array}{l}\text { Mastectomy or } \\
\text { lumpectomy with ALND }\end{array}$ & $\begin{array}{l}\text { R: R } 7.5 \mathrm{mg} / \mathrm{mL} \\
\text { solution } 20 \mathrm{~mL} \\
\text { C: NS } 20 \mathrm{~mL}\end{array}$ & The wound & $\begin{array}{l}\text { PP was lower at } \\
2,4 \text { and } 6 \mathrm{~h} \text { after } \\
\text { surgery }\end{array}$ & [18] \\
\hline $\begin{array}{l}\text { Albi- } \\
\text { Feldzer } \\
\text { [2013] }\end{array}$ & $\begin{array}{l}\text { evaluate the } \\
\text { influence of } R \\
\text { wound infiltration }\end{array}$ & $\begin{array}{l}\text { Conservative surgery with } \\
\text { ALND, MRM with or } \\
\text { without ALND }\end{array}$ & $\begin{array}{l}\text { R: } 0.375 \% \text { R } 3 \text { mg/ } \\
\text { kg mixed with } \\
\text { saline } \\
\text { C: Saline solution }\end{array}$ & $\begin{array}{l}\text { the wound, the } 2 \text { nd \& } 3 r d \text { intercostal } \\
\text { spaces and the humeral insertion of } \\
\text { major pectoralis }\end{array}$ & $\begin{array}{l}\text { decreased } \\
\text { immediate PP } \\
\text { ( } \leq 90 \text { min })\end{array}$ & [19] \\
\hline
\end{tabular}

ALND axillary lymph node dissection; $B$ bupivacaine; $C$ control; MRM modified radical mastectomy; NS normal saline; $R$ ropivacaine; PP postoperative pain

The incidence of PONV in the two groups remained similar. However, from $6 \mathrm{~h}$ to $12 \mathrm{~h}$ after operation, PONV occurred in 6 patients in Group A and 12 in Group B. This difference might due to the side-effects of higher tramadol requirement in Group B. At 3-months follow-up, no significant differences were discovered with regard to the incidence of chronic pain. The mechanism of chronic pain is complicated, and it is still poorly controlled. Although our intervention decreased the postoperative pain more effectively, no surgical, demographic, and psychosocial factors that influenced chronic pain after breast surgery considered [21]. It has been reported that $30 \% \sim 51 \%$ of patients suffered from persistent pain after breast cancer surgery [2]. In our study, $51.35 \%$ of patients in Group A and $43.24 \%$ in Group B suffered from chronic pain. Nearly half of the patients are tortured by chronic pain. Therefore, it is still regarded as a great challenge to explore the reduction and treatment of chronic pain after breast cancer surgery. Furthermore, combined with the other paincontrol methods, local infiltration anesthesia might further reduce the occurrence of postoperative acute pain, and even have positive effects on chronic pain.

However, there are certain limitations in this study that require consideration. Firstly, the sample size is small, and so it is not sufficient to perform subgroup analysis. Secondly, follow-up of the patient's pain after 3-months was not evaluated.

\section{Conclusions}

In conclusion, ropivacaine infiltration of two drainage exit sites effectively decreased the degree of postoperative acute pain and analgesic requirements within $24 \mathrm{~h}$, and meanwhile improved patients' quality of recovery. Further large scale studies are warranted to study the outcomes in the future, and explore efficient approach that relieve pain after mastectomy in long run.

\section{Abbreviations \\ PACU: Post-anesthesia care unit; PONV: Postoperative nausea and vomiting; VAS: Visual analogue scale; NSAIDs: Nonsteroidal anti-inflammatory drugs; BMI: Body mass index; SD: Standard deviation; ANOVA: Analysis of variance; PBI: Pain burden index; PVB: Paravertebral nerve block; ALND: Axillary lymph node dissection; SLNB: Sentinel lymph node biopsy}

\section{Acknowledgements}

We thank our colleagues at the Department of Anesthesiology, National Cancer Center/National Clinical Research Center for Cancer/Cancer Hospital, Chinese Academy of Medical Sciences and Peking Union Medical College, Beijing, 100021, China.

\section{Authors' contributions}

WBN contributed to study design, data collection and analysis, drafting of manuscript. GHZ and ZH contributed to study design, data collection and analysis, drafting of manuscript. YT and KXY contributed to the study design, data analysis and interpretation, and revised the manuscript. SL contributed 
to data analysis, and revised the manuscript. All authors have read and approved the final manuscript.

\section{Funding}

This study was funded by Beijing Hope Run Special Fund of Cancer Foundation of China (LC2019B11), and Sanming Project of Medicine in Shenzhen, Cancer Pain Treatment and Perioperative Medical Team of Professor Li Sun in Cancer Hospital, Chinese Academy of Medical Sciences. The funders had no role in study design, data collection and analysis, preparation of the manuscript, or decision to publish.

\section{Availability of data and materials}

All the data used and analyzed are available from corresponding authors upon the reasonable request.

\section{Ethics approval and consent to participate}

This study was approved by the ethics committee of National Cancer Center/Cancer Hospital, Chinese Academy of Medical Sciences and Peking Union Medical College (IRB Approval Number: 20/351-2135). Written informed consent was obtained from all participants.

\section{Consent for publication}

Not applicable.

\section{Competing interests}

The authors declare that they have no competing interests.

\section{Author details}

'Department of Anesthesiology, National Cancer Center/National Clinical Research Center for Cancer/Cancer Hospital, Chinese Academy of Medical Sciences and Peking Union Medical College, Beijing 100021, China.

${ }^{2}$ Department of Breast Surgery, National Cancer Center/National Clinical Research Center for Cancer/Cancer Hospital, Chinese Academy of Medical Sciences and Peking Union Medical College, Beijing 100021, China. ${ }^{3}$ Department of Anesthesiology, National Cancer Center/National Clinical Research Center for Cancer/Cancer Hospital \& Shenzhen Hospital, Chinese Academy of Medical Sciences and Peking Union Medical College, Shenzhen 518116, China.

Received: 13 May 2020 Accepted: 24 September 2020

Published online: 06 October 2020

\section{References}

1. Apfelbaum JL, Chen C, Mehta SS, Gan TJ. Postoperative pain experience: results from a National Survey Suggest Postoperative Pain Continues to be undermanaged. Anesth Analg. 2003;97:534-40.

2. Wang L, Gordon GH, Sean SA, Romerosa B, Kwon HY, Kaushal A, et al. Predictors of persistent pain after breast cancer surgery: a systematic review and meta-analysis of observational studies. CMAJ. 2016:188:352-61.

3. Gartner R, Jensen MB, Nielsen J, Ewertz M, Kroman N, Kehlet H. Prevalence of and factors associated with persistent pain following breast cancer surgery. JAMA. 2009:302:1985-92.

4. Nadeem M, Sahu A. Ultrasound guided surgery under Dilutional local anesthesia and no sedation in breast cancer patients. Surgeon. 2020;18:914.

5. Rao KV, Ludbrook G, van Wijk RM, Hewett PJ, Moran JL, Thiruvenkatarajan V, et al. Comparison of ultrasound-guided transmuscular quadratus lumborum block catheter technique with surgical pre-peritoneal catheter for postoperative analgesia in abdominal surgery: a randomised controlled trial. Aneasthesia. 2019;74:1381-8.

6. Park KU, Kyrish K, Yi M, Bedrosian I, Caudle AS, Kuerer HM, et al. Opioid use after breast-conserving surgery: prospective evaluation of risk factors for high opioid use. Ann Surg Oncol. 2020:27:730-5.

7. Del Vecchio G, Spahn V, Stein C. Novel opioid analgesics and side effects. ACS Chem Neurosci. 2017:8:1638-40.

8. Duthie DJ, Nimmo WS. Adverse effects of opioid analgesic drugs. Br J Anaesth. 1987:59:61-77.

9. Naja ZM, Naccache N, Ziade F, El-Rajab M, Itani T, Baraka A. Multilevel nerve stimulator-guided paravertebral block as a sole anesthetic technique for breast cancer surgery in morbidly obese patients. J Anesth. 2011;25:760-4.
10. Park KU, Kyrish K, Terrell J, Yi M, Caudle AS, Hunt KK, et al. Surgeon perception versus reality: opioid use after breast cancer surgery. Surg Oncol. 2019;119:909-15.

11. Kairaluoma PM, Bachmann MS, Korpinen AK, Rosenberg PH, Pere PJ. Singleinjection paravertebral block before general anesthesia enhances analgesia after breast cancer surgery with and without associated lymph node biopsy. Anesth Analg. 2004;99:1837-43.

12. Baudry G, Steghens A, Laplaza D, Koeberle P, Bachour K, Bettinger G, et al. Ropivacaine infiltration during breast cancer surgery: postoperative acute and chronic pain effect. Ann Fr Anesth Reanim. 2008;27:979-86.

13. Johansson A, Kornfält J, Nordin L, Svensson L, Ingvar C, Lundberg J. Wound infiltration with ropivacaine and fentanyl: effects on postoperative pain and PONV after breast surgery. J Clin Anesth. 2003;15:113-8.

14. Johansson A, Axelson J, Ingvar C, Luttropp H-H, Lundberg J. Preoperative ropivacaine infiltration in breast surgery. Acta Anaesthesiology Scand. 2000; 44:1093-8.

15. Rica MA, Norlia A, Rohaizak M, Naqiyah I. Preemptive ropivacaine local anesthetic infiltration versus postoperative ropivacaine wound infiltration in mastectomy: postoperative pain and drain outputs. Asian J Surg. 2007;30: 34-9.

16. Talbot H, Hutchinson SP, Edbrooke DL, Wrench I, Kohlhardt SR. Evaluation of a local anaesthesia regimen following mastectomy. Anesthesia. 2004;59: 664-7.

17. Nirmala J, Harsh K, Padmaja D, Gopinath R. Role of wound instillation with bupivacaine through surgical drains for postoperative analgesia in modified radical mastectomy. Indian J Anesthesia. 2015:59:15-20.

18. Vigneau A, Salengro A, Berger J, Rouzier R, Barranger E, Marret E, et al. A double blind randomized trial of wound infiltration with ropivacaine after breast cancer surgery with axillary nodes dissection. BMC Anesthesiol. 2011; 11:23.

19. Albi-Feldzer A, Mouret-Fourme EE, Hamouda S, Motamed C, Dubois PY, Jouanneau $L$, et al. A double-blind randomized trial of wound and intercostal space infiltration with ropivacaine during breast cancer surgery: effects on chronic postoperative pain. Anesthesiology. 2013;118:318-26.

20. Kehlet $\mathrm{H}$, Jensen TS, Woolf CJ. Persistent postsurgical pain: risk factors and prevention. Lancet. 2006;367:1618-25.

21. Tara L, Emily D, Nantthasorn Z, Tari A, Laura D, Rob R, et al. Chronic pain after breast surgery: a prospective, observational study. Ann Surg Oncol. 2018;25:2917-24.

\section{Publisher's Note}

Springer Nature remains neutral with regard to jurisdictional claims in published maps and institutional affiliations.

Ready to submit your research? Choose BMC and benefit from:

- fast, convenient online submission

- thorough peer review by experienced researchers in your field

- rapid publication on acceptance

- support for research data, including large and complex data types

- gold Open Access which fosters wider collaboration and increased citations

- maximum visibility for your research: over $100 \mathrm{M}$ website views per year

At BMC, research is always in progress.

Learn more biomedcentral.com/submissions 